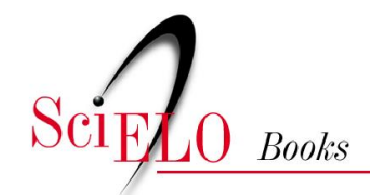

\title{
Reflexões sobre a concepção holística da investigação histórica
}

\author{
Jozimar Paes de Almeida
}

ALMEIDA, JP. Reflexões sobre a concepção holística da investigação histórica. In: A extinção do arco-íris: ecologia e história [online]. Rio de Janeiro: Centro Edelstein de Pesquisa Social, 2008, pp. 12-18. ISBN 978-85-99662-69-4. Available from SciELO Books $<$ http://books. scielo.org $>$.

\section{(1) $(0)$}

All the contents of this chapter, except where otherwise noted, is licensed under a Creative Commons Attribution-Non Commercial-ShareAlike 3.0 Unported.

Todo o conteúdo deste capítulo, exceto quando houver ressalva, é publicado sob a licença Creative Commons Atribuição Uso Não Comercial - Partilha nos Mesmos Termos 3.0 Não adaptada.

Todo el contenido de este capítulo, excepto donde se indique lo contrario, está bajo licencia de la licencia Creative Commons Reconocimento-NoComercial-CompartirIgual 3.0 Unported. 


\section{Reflexões sobre a concepção holística da investigação histórica}

A ordem mais bela é como um montão de lixo jogado ao acaso.

Heráclito

Uma das expressões mais comumente veiculadas por autores que analisam o processo do conhecimento é a da iluminação do objeto estudado para que os sujeitos do processo consigam visualizá-lo integralmente. Este movimento de iluminação é dirigido e produzido pelo sujeito. Ambos, assim como o objeto, estão em constante devir, pela destrutibilidade da permanência.

A apreensão do real pela luz, como um dos primeiros atos realizados por Deus, ou como representação do conhecimento (fogo celeste) por Prometeu, trouxe dúvidas veiculadas na alegoria da caverna de Platão ${ }^{7}$, ao desvendar que as disposições espaciais dos elementos que compõem o processo do conhecimento privilegiam apenas alguma parte deste conhecimento instituindo-o como verdadeiro.

As trevas da noite perpassam este trabalho, fruto de "flashes", que não pretende ser farol numa ilha deserta a orientar navegantes incautos.

Está posta a jangada no mar da incerteza e da inconstância; não há portos estáticos ou flutuantes que possam dar conta do turbilhão de elementos que integram este oceano. $\mathrm{O}$ abutre da certeza, a razão linear e total em História, esfomeado, voa em círculos sobre o meu corpo, da dúvida em degeneração/criação. Vencê-lo-ei? Deixarei de ser $U m$ de La Boétie, e voltarei a ser múltiplo, poli dimensional, signo? Enquanto $U m$ não sou composto e vivo sobre e sob os elementos que integram o universo?

Karl Marx, que analisou profundamente como se realizam as relações entre os homens, enfatizando as relações sociais como atividade produtiva determinante de uma sociedade, não deixou de assinalar a grande importância a terra, afirmando:

Portanto, o trabalho não é a única fonte dos valores de uso que produz, da riqueza material. Dela o trabalho é o pai, como diz William Pety, e a terra a mãe ${ }^{8}$.

Radicalizando - diria que a terra, assim também como os outros objetos que compõem o universo, têm sua importância intrínseca ao seu próprio existir e extrínseco no que se refere às relações estabelecidas com o Todo. O homem é uma parte deste universo e é composto por este, no entanto ele se auto-declara ter o poder de estipular a importância dos outros componentes em relação ao seu interesse.

\footnotetext{
${ }^{7}$ A alegoria da caverna transmite as diversas fases percorridas no processo de compreensão do real. Utiliza um enredo no qual vários personagens presos no interior de uma caverna tentam compreender o seu mundo pelas sombras dos objetos que são projetados em uma parede da caverna. Até que um destes personagens é· libertado e sai da caverna passando por várias fases de luminosidades, até chegar à luz do sol. Cf. PLATÃO - A República. Livro VII. Comentários Bernard Piettre, Trad. EIza Moreira Marcelina. Brasília, Editora Universidade de Brasília, 1985.

${ }^{8}$ MARX, Karl. O Capital. Trad. Régis Barbosa e Flávio R. Kothe, 2. a edição. São Paulo, Nova Cultural, 1985, Livro I, Volume I, p. 51.
} 
O homem é um ser cultural e histórico, no entanto é também um ser biológico (natural).

$\mathrm{O}$ fato da vida física e espiritual do homem estar vinculada à natureza não tem nenhum outro sentido a não ser que está vinculada consigo mesmo, pois o homem é uma parte da natureza'.

A relação homem/natureza ocorre simultaneamente e necessariamente se interagem, produzindo e resultando ações oriundas deste relacionamento.

Desta forma, ao estudar esta interação poderei tentar iluminar algumas partes da existência do homem, em sua busca incessante da resposta de seus enigmas.

Este intricado nó górdio pode ser resolvido pelo fio da lâmina?

O corte epistemológico mutila a complexidade dinâmica das múltiplas relações entre os homens e a natureza. Apesar disso, opto por enveredar através de conceitos, sem realizar uma exegese, que possam esclarecer a relação homem/natureza.

O homem é composto por elementos integrantes do universo, então necessariamente: ocupa um espaço, movimenta-se no espaço e no tempo pela sua duração/degradação. No entanto enquanto vivente possui características fisiológicas e sociais inerentes à sua espécie.

O fator diferenciador da relação homem/natureza é a consciência, exemplo da singularidade humana composta pela cultura e raciocínio.

Optei por privilegiar nesta proposta de estudo de história e ecologia, a atividade humana exercida com determinados fins, por despir com o rasgar das vestes, a musa inspiradora, a natureza.

A ação que o homem/natureza exerce sobre a natureza, portanto sobre si mesmo, enquanto pertencente a ela, é dirigida para determinados fins. Esta atividade de criação/transformação é denominada trabalho.

Por trabalho entendo a criação do homem/natureza. Esta atividade integra-se simultaneamente à noção de cultura e raciocínio, energias transformadoras internas à sua corporalidade, não construídas necessariamente por contato direto com o meio natural circundante.

Antes de tudo, o trabalho é um processo entre o homem e a natureza, um processo em que o homem por sua própria ação, media, regula e controla seu metabolismo com a natureza. Ele mesmo se defronta com a matéria natural. Ele põe em movimento as forças naturais pertinentes à sua corporalidade, braços e pernas, cabeça e a fim de apropriar-se da matéria natural numa forma útil para sua própria vida.

Ao atuar, por meio desse movimento, sobre a natureza externa a ele e ao modificála, ele modifica, ao mesmo tempo, sua própria natureza ${ }^{10}$

Para Marx, a ação de apropriação da natureza é denominada processo de trabalho:

é atividade orientada a um fim para produzir valores de uso, apropriação do natural para satisfazer a necessidades humanas, condição universal do metabolismo entre o homem e a natureza, condição natural eterna da vida humana e, portanto, independente de qualquer forma dessa vida, sendo antes igualmente comum a todas as suas formas sociais ${ }^{11}$.

Para sua sobrevivência, necessariamente o homem relaciona-se com a natureza constituindo

9. MARX Karl. Nationalekonomie und Philosophie, p. 148. Apud SCHIMIDT, Alfred. El Concepto de Naturaleza em Marx. España, Siglo Veintiuno. 1976, p. 88.

${ }^{10}$ MARX, Karl. O Capital. 2. ${ }^{a}$ ed., S. Paulo, Nova Cultural, 1985, Livro I, Vol. 1, p. 149.

${ }^{11}$ Ibid., p. 153. 
um processo acentuadamente desestabilizador desta, pois não retira somente o necessário para sua reprodução física, mas para satisfazer necessidades que são socialmente fabricadas, as quais surgem com o crescimento da complexidade sócio-econômica e cultural das sociedades, com o crescimento da divisão e da estratificação social no interior dos grupos humanos.

O impacto do homem sobre o meio ambiente, portanto, vai variar historicamente de acordo com o modo de produção, a estruturação de classes, o aparato tecnológico e o universo cultural de cada sociedade $^{12}$.

No processo de relação homem/natureza, estabelece-se o trabalho humano, como atividade própria, para o controle da natureza. Através do trabalho, os homens contraem entre si determinadas relações sociais, constituindo com a natureza uma relação biossocial pelas atividades nela realizadas.

As relações dos homens com a natureza constituem o pressuposto para as relações recíprocas dos homens entre si, a dialética do processo de trabalho como processo natural se amplia à dialética da história humana em geral $^{13}$.

Para o homem o trabalho é criador de "valores" no plano formal, a natureza o é no plano material, a separação entre substância natural e trabalho não é de maneira nenhuma absoluta ${ }^{14}$.

O processo de trabalho é uma forma determinada de efetivação da matéria natural, gerando o produto social. Portanto, forma e matéria serão singularizadas em decorrência de suas relações instituídas obrigatoriamente como substâncias naturais - força humana natural e matéria natural.

O conceito valor estabelecido pelo antropocentrismo é aplicado à matéria natural, quando esta é vista pela ótica de sua utilidade para o homem, no entanto deve-se adotar um princípio básico não antropocêntrico, em relação a toda matéria natural, pois ela existe indiferente às relações estabelecidas com o homem neste universo.

Marx adota o conceito de valor de uso com uma perspectiva de utilização dessa matéria natural sob a ótica das "necessidades" sociais (criadas culturalmente), que variam, portanto segundo as sociedades.

É importante expor aqui que determinadas matérias naturais são indispensáveis às necessidades biológicas para a existência do ser vivo (resguardo o que se conhece por existência, limitado ao espaço e tempo até agora explorado pelo homem).

O valor de uso (fruto da matéria natural) pode ser ou não produto de um trabalho, em sua maioria (excluindo elementos indispensáveis para a vida) é resultado da construção cultural da sociedade em que ele está inserido. Assim também o conceito valor de troca adquire características sociais de intercâmbio, de toda matéria que tem valor de uso, por sua natureza.

O ecossistema é constituído por uma relação dinâmica entre matérias naturais (fonte primordial de toda e qualquer relação humana), que ao passarem pelo processo de interação, podem transformar seus elementos fundamentais, modificando a sua essência. Esta modificação pode exterminar, ou destruir parcialmente os seres vivos que necessitam biologicamente das condições originais ou propícias do ecossistema para sobreviver.

Extermínio é uma ação realizada deliberadamente ou não pelo homem sobre determinadas espécies de seres vivos. Quando realizada deliberadamente é para não prejudicar a racionalidade proposta pelo homem à natureza visando simplesmente a produção.

\footnotetext{
${ }^{12}$ LAGO, Antonio e PADUA, José Augusto. O que é Ecologia. São Paulo, Brasiliense, 1984, p. 29.

${ }^{13}$ SCHMIDT, Alfred. El Concepto de Naturaleza en Marx. España, Siglo Veintiuno, 1976, p. 57.

${ }^{14}$ Ibid., p . 74.
} 
Utilizo a agroindústria como objeto de análise, por se inserir em uma sociedade capitalista, com as especificidades de uma junção da produção industrial e agrícola:

O capitalismo é do ponto de vista histórico, bem mais desenvolvido na indústria: podemos admitir que o motor de mudança na agricultura é o descontentamento dos capitalistas industriais ${ }^{15}$.

As mudanças na agricultura se aprofundaram com o início da industrialização pesada (1956/1961). A mecanização agrícola, a utilização de combustíveis, a adubação química, as sementes selecionadas, os defensivos e os insumos destinados à criação animal (medicamentos, inseminação artificial, etc.) fazem parte desta tecnologia, utilizada para intensificar a produção na agropecuária.

Percebe-se nos Estados de São Paulo e Rio Grande do Sul, uma acentuada utilização tecnológica, comparada às outras unidades da federação, pelos dados indicadores da tecnificação agrícola no Brasil de 1970-1975.

\begin{tabular}{|c|c|c|c|c|}
\hline \multirow[t]{2}{*}{ Unidades da Federação } & \multicolumn{2}{|c|}{$\begin{array}{c}\text { Uso de } \\
\text { Força Mecânica }\end{array}$} & \multicolumn{2}{|c|}{$\begin{array}{c}\text { Uso de } \\
\text { Fertilizantes }\end{array}$} \\
\hline & 1970 & 1975 & 1970 & 1975 \\
\hline Bahia & 2,0 & 7,9 & 9,9 & 13,3 \\
\hline Minas Gerais & 6,8 & 15,3 & 30,5 & 39,2 \\
\hline Espírito Santo & 3,7 & 11,3 & 13,0 & 23,9 \\
\hline Rio de Janeiro $(+\mathrm{Gb})$ & 8,7 & 15,8 & 23,7 & 26,5 \\
\hline São Paulo & 25,5 & 33,4 & 47,5 & 62,0 \\
\hline Paraná & 8,8 & 25,6 & 14,8 & 27,6 \\
\hline Santa Catarina & 10,8 & 10,5 & 33,4 & 42,1 \\
\hline Rio Grande do Sul & 11,3 & 37,0 & 54,5 & 58,5 \\
\hline Goiás & 13,9 & 27,2 & 5,6 & $19,7^{14}$ \\
\hline
\end{tabular}

Numa sociedade capitalista, que é uma sociedade de classes, a ciência destina-se a gerar o saber necessário para garantir a produção e a reprodução dos processos vitais desta sociedade, cuja forma é determinada, fundamentalmente pela classe dominante...

Se a própria ciência tem um caráter de classe na sociedade capitalista, com muito mais razão o terá a tecnologia, que é a aplicação dessa ciência ao processo

\footnotetext{
${ }^{15}$ AMIN, Samir e VERGOPOUlos, Kostas. A Questão Agrária e o Capitalismo. Trad. Beatriz Rezende, Rio de Janeiro, Paz e Terra, 1971, p. 63.

${ }^{16}$ GRAZIANO DA SILVA, José \& KAGEYAMA, Ânge1a A. A Produtividade e emprego na agricultura Brasileira. In: BELlUZZO, Luiz Gonzaga \& COUTINHO, Renata (Org.) - Desenvolvimento Capitalista no Brasil. São Paulo, Brasiliense, 1983, (2), p. 207, Fonte: Censos agrícolas de 1970 e 1975.
} 
produtivo... A tecnologia é, portanto, uma relação social e não apenas um conjunto de "coisas". Como se poderia pensar ao olhar as máquinas, os adubos químicos, as sementes, etc...

Ora, sabemos que no sistema capitalista o objetivo da produção é o lucro; portanto, a tecnologia que lhe é adequada, que permite gerar mais lucros. ${ }^{17}$

$\mathrm{E}$, é bem neste contexto, e de forma consciente que a agroindústria se insere. Afinal, agricultura também é empresa, e empresa enquanto tal opera com receita e despesa.

O processo tecnológico atua na agricultura, intensificando o ritmo da jornada de trabalho, alterando as condições naturais do solo, por meio de substâncias fisioquímicas e aumentando a velocidade de rotação do capital através de alterações biológicas para reduzir o período de produção.

E cada progresso da agricultura capitalista não só é um progresso na arte de saquear o trabalhador, mas ao mesmo tempo na arte de saquear o solo, pois cada progresso, no aumento da fertilidade por certo período é simultaneamente um progresso na ruína das fontes permanentes dessa fertilidade ${ }^{18}$.

O saque do ecossistema recebe neste trabalho de investigação uma atenção quase exclusiva. Este privilégio ocorre para ressaltar bem claramente o grave problema da exaustão do ecossistema. Esta exaustão não decodificada na maioria das vezes pelo homem, é devida às diferenças de formas de expressão comunicativa entre a natureza e o homem ou ainda por interesses econômicos imediatos particulares.

Estudar e analisar a ecologia pela forma como os homens instituem as suas relações sociais e seu modo de produção, está diretamente ligado a um conceito holístico de investigação extremamente dinâmico, das interações homem/natureza que pode e deve ser uma nova área de pesquisa para o historiador.

O materialismo histórico elaborado por Marx fundou suas concepções de investigação da história sobre bases reais, pois através delas podemos realizar constatações empíricas pela materialidade de suas existências.

Comprovou enquanto bases reais, a existência de um patrimônio corporal dos seres humanos e as relações que este desenvolve com o resto da natureza.

A natureza é a condição material primeira de existência da espécie humana, o homem é fundamentalmente constituído por ela. Esta natureza por sua vez sofreu transformações pela ação concreta dos homens em sociedade, com o objetivo de assegurarem melhores condições de sobrevivência.

Através destes fundamentos Marx desenvolve sua análise demonstrando que a ação dos homens entre si e com a natureza é real e irá variar de acordo com o que produzem, quanto como a maneira pela qual o produzem. Os indivíduos são, portanto resultantes de suas condições materiais de produção.

A confecção de uma lança e de um míssil nuclear demonstram diferentes relações entre os homens, como também diferentes relações com a natureza.

Pois bem, é chegada a hora (que rufem os tambores!), pois os abutres encastelados em suas torres de marfim passarão incólumes sobre as próximas explanações.

\footnotetext{
${ }^{17}$ GRAZIANO DA SILVA, José \& KAGEYAMA, Ângela A. Op. cit. pp. 192/193.

${ }^{18}$ MARX, Karl. O Capital. Trad. Régis Barbosa e Flávio R. Kothe, 2. a ed., São Paulo, Nova Cultural, 1985 , Livro I, Vol. 2, p. 102.
} 
O homem é matéria natural e enquanto matéria recebe e emite energia proveniente dos átomos que o compõe ou incorpora do exterior. Energia é a propriedade que tem a matéria de realizar transformações, pois ela é composta por átomos que se movimentam.

Quando o homem come, incorpora energia sob a forma de alimentos e a libera por exemplo, sob a forma de calor.

No entanto o homem é possuidor de uma característica diferenciadora em relação às outras matérias, já que todas recebem e emitem energia. Ele pode orientar a emissão de parte de sua energia para realizar determinadas tarefas, que lhe é conferida de acordo com as condições materiais de produção num dado momento histórico.

Assim também como no mesmo momento em que o homem está emitindo esta energia orientada, ele sofre modificações internas à sua corporalidade, transformando a natureza e transformando-se enquanto matéria natural num processo dialético.

Quando o homem pulveriza sua plantação com biocidas para destruir "pragas", irá sofrer um retorno de sua própria energia transmitida sob a forma de doenças, ocasionadas pela ingestão de alimentos contaminados pelos biocidas.

Esta capacidade humana de orientação da aplicação da energia é resultante e se desenvolveu pelas transformações ocorridas nas relações entre os homens e destes com a natureza. Ambos se modificam na dinâmica de suas relações, determinando características específicas do homem que é a natureza.

O fato do homem refletir sobre sua própria existência, faz parte de sua essência natural? Afinal o que somos? De onde viemos? Para onde vamos? São os dilemas da história humana.

O homem existe enquanto ser humano por estabelecer relações de vivência com indivíduos da mesma espécie; estas relações entre os homens dirigem a aplicação de energia para a realização de um determinado trabalho.

A matéria humana natural relaciona-se entre si e com outras matérias possuidoras de características e propriedades diferentes, ela forma interconexões dinâmicas que não se realizam simplesmente em uma linearidade ou de superfície como rede, tecido ou tela.

É como a brincadeira de derrubar as peças de dominó - elas são colocadas em pé sobre uma superfície e justapostas, para que com a queda de uma peça esta derrube a peça vizinha, iniciando uma reação em cadeia com o objetivo de derrubar todas as peças.

Este exemplo citado pretende ilustrar que as ligações retilíneas ou de superfície são incompletas para demonstrar as relações existentes entre as matérias. A multidimensionalidade dinâmica das relações energéticas é mais apropriada para expor que a energia que atua no espaço em todas as direções.

Agora, este abusado escritor vai tocar teu corpo, meu "paciente" leitor, não se preocupe! Vou tocar apenas teus olhos.

Teu corpo é formado por órgãos, estes por tecidos que são agregados de moléculas, compostas por átomos.

Os átomos consistem em partículas, e estas partículas não são feitas de qualquer substância material. Quando as observamos, nunca vemos qualquer substância; o que vemos são modelos dinâmicos que se convertem continuamente nos outros - a contínua dança da energia ${ }^{19}$.

\footnotetext{
${ }^{19}$ CAPRA, Fritjof. O ponto de mutação, trad. Álvaro Cabra1, São Paulo, Cultrix, 1987.
} 
Machuquei? Desculpe-me, é a tua existência que ficará perdida na memória como lágrimas sob a chuva, pois é tua curta vista que faz ver coisas fixas e permanentes neste universo de destruição/criação.

O universo e a partícula estão para a energia, tanto quanto o teu corpo está para ambos, portanto encontro o universo em teu corpo, como se fosse uma partícula holográfica, que manifesta simultaneamente as características da totalidade e da parte, o UM e o MÚLTIPLO ao mesmo tempo.

A questão ecológica está inserida no campo da história, ambos estão intrinsecamente ligados. Procuro desenvolver neste trabalho as comprovações de tal enredamento. 